\title{
Psychological Well-being among the Left-behind Elderly in Ethnic Miao Villages of Guizhou Province
}

\author{
Jian $\mathrm{Hu}$ \\ Guizhou University of Finance and Economics, Guiyang, China \\ E-mail: jianhucdc@126.com
}

\begin{abstract}
Objective] To describe the psychological well-being and analyze relevant factors among the left-behind elderly in ethnic Miao villages. [Methods] A cross sectional survey was conducted with a structured questionnaire among the 192 left-behind elderly at the age of 60 or older in July 2011 in three Miao minority villages in Shibing county, Qiandongnan Miao and Dong autonomous prefecture of Guizhou province, P. R. China. The psychological well-being was measured by the social function, mental health, and sensibility function and vitality dimension of the medical outcomes study 36-item short form for health survey (SF-36). [Results] The total score of the psychological well-being was $(67.32 \pm 1.46)$. The score of social function, mental health, sensibility function and vitality dimension was $(72.59 \pm 1.98),(69.88 \pm 1.48),(66.15 \pm 3.32)$, and $(60.68 \pm 1.47)$, respectively. There was a significantly difference in the psychological well-being among the left-behind elderly with different age $(t=-2.393, P=0.018)$, family yearly income per person $(F=2.757, P=0.029)$, economic resource $(F=5.073$, $P=0.007)$, walking with difficulty $(t=2.145, P=0.037)$, vision disorder $(t=2.067, P=0.040)$, illness in the last two weeks $(t=8.891, P=0.000)$, chronic disease $(t=7.827, P=0.000)$, and physical examination $(t=-2.977, P=0.003)$. [Conclusion] The status of psychological well-being is bad among the left-behind elderly in Miao minority villages.
\end{abstract}

Keywords- Left-behind elderly; Psychological well-being; Ethnic Miao

\section{INTRODUCTION}

The psychological problems among the rural left-behind elderly were concerned [1]. Guizhou province is located in the southwest of P. R. China, where many ethnic minority groups live. The ethnic Miao population is the second large population in Guizhou province, next to the ethnic Han. Miao villages are often located in remote mountainous areas far from cities. Due to constraints such as geography, culture, and economy, young adults in Miao villages mostly were migrants as workers in cities. Most of their parents became the rural left-behind elderly, who were at the age of 60 or older, still remaining in the rural life while their children lived outside their county for half a year or longer. However, researches on psychological well-being were rarely reported on the rural left-behind elderly, especially in Miao villages [2-3]. This study was conducted in July 2011 in Shibing county of Qiandongnan Miao and Dong autonomous prefecture, Guizhou province. The aims of the study were to explore the psychological well-being status of the left-behind elderly in Miao villages, to analyze relevant factors of the psychological well-being, and to provide a scientific basis for developing and improving the rural health care policy for the elderly.

\section{METHODS}

\section{A. Study Area and Population}

Shibing County is a representative county of ethnic minority areas and national poverty alleviation and development. A total of 241 people at the age of 60 or older were interviewed in the three Miao villages (Lishanping, Tunshang, and Bantun) of Yangliutang town, Shibing County, including 192 left-behind old people.

\section{B. Data collection and Measurement}

The project researchers and the trained graduate students were investigators. The local personnel of township health centers, village clinics and village committee organized the elderly to village clinics, where a one to one anonymous interview survey was conducted by investigators with the help of local Miao translators. The questionnaire of psychological well-being among the rural left-behind elderly was designed based on the medical outcomes study 36-item short form for health survey (SF-36) [4], and the fourth family health inquiry questionnaire in China's health service investigation and study in 2008 [5]. The survey included five aspects as follows: (1) The socio-demographic characteristics of the rural left-behind elderly, e.g., gender (male, female), age (60-69, 70-79, $\geq 80$ ), marriage (married, widowed or divorced), original occupation (farmer, non-farmer), education (lower than primary school, primary school, junior high school and above), capability to speak Han language (yes, no), religion (yes, no), ethnic type (ethnic Han, ethnic Miao), family poverty status (yes, no), and family yearly income per person; (2) Health related behavior, e.g., physical exercise (yes, no), smoking (yes, no), and drinking frequency (3 time or more per week, 1-2 times per week, occasional drink); (3) Illness and disability (yes, no), e.g., illness in the last two weeks (yes, no), chronic disease (yes, no), walking with difficulty (yes, no), vision disorder (yes, no), listening with difficulty (yes, no), speaking with difficulty (yes, no), and daily life care (yes, no); (4) Social support condition, e.g., living style (living alone or with their 
spouses, living with their children), meeting migrant children frequency (every six months or shorter, a year or longer), medical insurance (yes, no), endowment insurance (yes, no), economic source (themselves/their spouses, children, social relief), physical examination (yes, no), psychological health knowledge (yes, no), and taking care of grandchildren (yes, no); (5) Psychological well-being status, including four dimensions of social function, mental health, sensibility function, and vitality. Social function referred to the limited social activities for physical or emotional reasons. Mental health referred to the psychological depression and good adaptation. Sensibility function referred to the limited role activity for emotional reasons. Vitality referred to the individual's subjective feeling for their energy and fatigue. The original score in each dimension was transformed into 0 to 100 standard score [4]. The total score of the psychological well-being was an average score of the four dimensions. The maximum was 100 scores. The score is higher, the better the psychological well-being. Cronbach coefficient of the psychological well-being was 0.87 , which indicated a high internal consistency reliability of the questionnaire.

\section{Data Analysis}

$t$ or $F$ test was performed with SPSS17.0.

\section{RESULTS}

\section{A. Characteristics of the Left-behind Elderly}

About 55.2 percent of the left-behind elderly reported their ages from 60 to 69 years old, and 44.8 percent reported their ages above 70 years old. 94.3 percent reported an original occupation as farmer, 5.7 percent as non-farmer. 74.0 percent had married, and 26.0 percent had divorced or widowed. 62.0 percent of respondents reported the education of the lower than primary school; 28.6 percent reported the primary school; and 9.4 percent reported the junior high school or above. 33.3 percent reported the family poverty status, and 66.7 percent did not. As family yearly income per person, there were 31.3 percent in the lowest, 21.4 percent in the lower, 21.9 percent in the middle, 15.1 percent in the higher, and 10.4 percent in the highest group. With regard to economic resources, there were 46.9 percent from themselves or their spouses, 46.9 percent from their children, and 6.2 percent from the social relief. 87.5 percent lived with their children, and 12.5 percent lived alone or with their spouses. 97.4 percent had the medical insurance, and 2.6 percent had not. There were not any endowment insurance, pension institution, and association of the elderly in the surveyed villages. 21.4 percent walked with difficulty, and 78.6 percent did not. 52.1 percent had vision disorders, and 47.9 percent had not. 58.3 percent reported the illness in the last two weeks, and 41.7 percent did not. 51.0 percent reported chronic diseases, and 49.0 percent did not. 57.3 percent reported physical examinations, and 42.7 percent did not.

\section{B. Status of Psychological Well-being}

The total score of the psychological well-being was (67.32 \pm 1.46$)$ among the left-behind elderly. The score of social function, mental health, sensibility function and vitality dimensions was $(72.59 \pm 1.98), \quad(69.88 \pm 1.48)$, $(66.15 \pm 3.32)$, and $(60.68 \pm 1.47)$, respectively.

\section{Association of Psychological Well-being and Four Dimensions}

There was a statistically significant difference in the total score of the psychological well-being among the left-behind elderly with different age, family yearly income per person, economy source, walking with difficulty, visual disorder, and illness in the last two weeks, chronic disease, and physical examination. For example, the total score of the psychological well-being was statistically lower for the left-behind elderly at the age of 60-69 years old than for the left-behind elderly at the age of 70 years old or older. In addition, there was a statistically significant difference in the score of different dimension among the same characteristic of the left-behind elderly. For example, there was a statistically significant difference in the score of sensibility function among different age, but there was not any statistically significant difference in the score of other dimensions among different age. See Table 1. 
TABLE I. ASSOCIATION OF PHYSIOLOGY WELL-BEING AND DIFFERENT DIMENSION

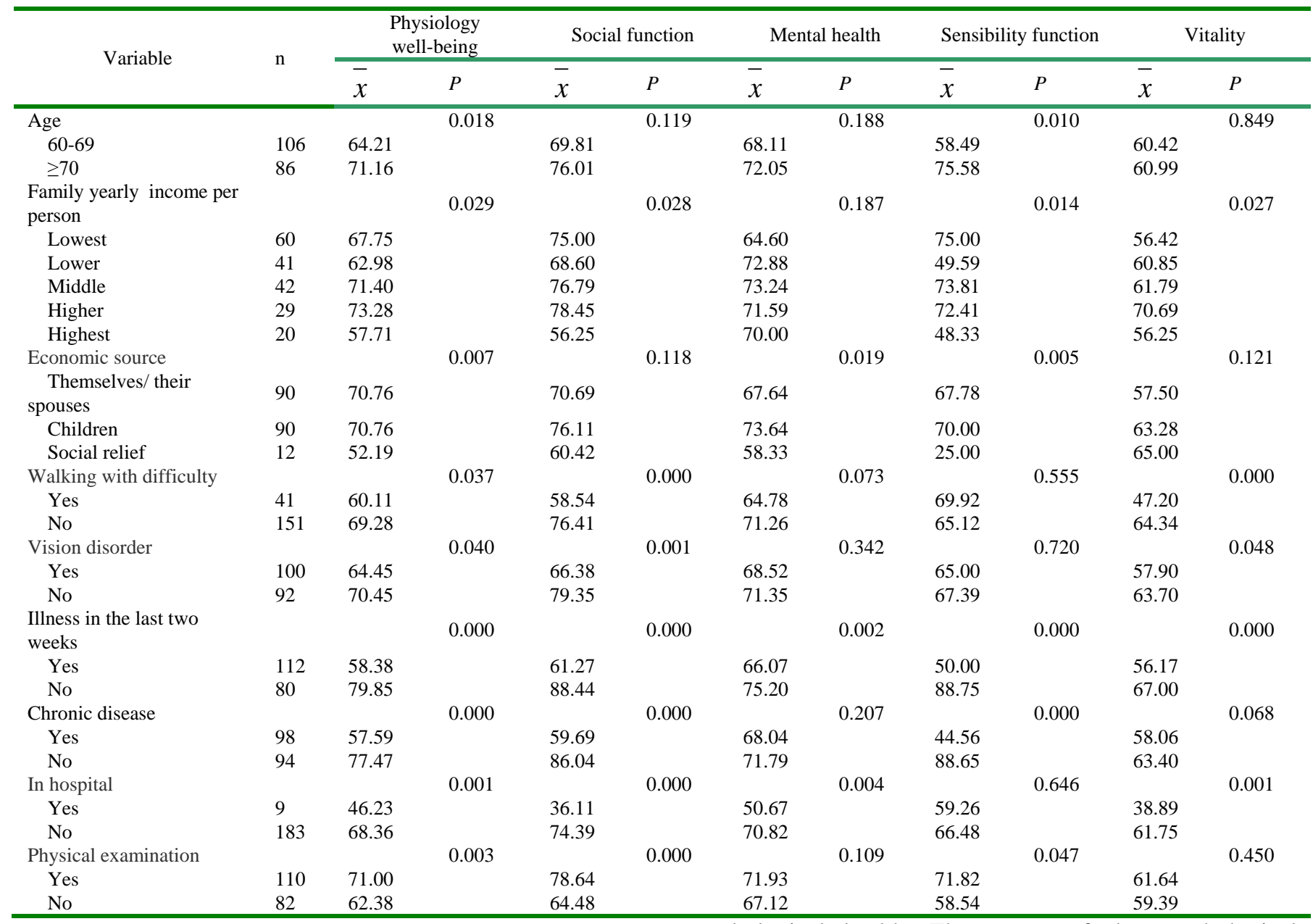

\section{DISCUSSION}

The results of this study showed that the total score of the psychological well-being was low among the left-behind elderly in Miao villages. The score of sensibility function or vitality was significantly lower than the score of sensibility function $(83.48 \pm 35.17)$, or vitality $(65.32 \pm 12.63)$ in other studies $(\mathrm{P}<0.01)$, respectively [6]. This suggests that the status of the psychological well-being was worse among the left-behind elderly in Miao villages. The left-behind elderly got less emotional supports, and felt tired themselves. In addition, The scores of the psychological well-being and sensibility function were lower for the left-behind elderly at the age of 60-69 years old than for the left-behind elderly at the age of 70 years old or above $(P<0.05)$, which was in contrast to the results in other studies [7]. This suggests that the status of the psychological well-being was worse for the lower age group than for the middle age group. The reasons may be that their children and society had not paid an attention on the need for care of the lower age group. Moreover, the results suggest that increasing the income level of the left-behind elderly and the efforts of social relief might improve their emotional supports, and their psychological health. The scores of the psychological well-being and of each dimension were lower among the left-behind elderly with severe disabilities and illnesses. This suggests that the left-behind elderly with severe disabilities and illnesses should be a key psychological intervention group, and corresponding measures might be taken for them to strengthen the counseling and intervention. Finally, the study indicated that physical examination might not only early prevent and treat mental illnesses, but also improve the mental health status of the left-behind elderly through increasing social engagement activities and emotional support efforts among the left-behind elderly.

\section{ACKNOWLEDGEMENT}

This study was financially supported by the National Social Science Fund Project of China (14BGL213).

\section{REFERENCES}

[1] M. Nie, Q. Wang, Y.S.Yao, "The progress of researches on psychological problems among the left-behind elderly and the empty-nest elderly in China", Chinese Journal of Gerontology, vol. 31, pp.2364-2366, Dec. 2011. 
[2] Z.Y. Chen, "Mental health status and psychological intervention among the left-behind elderly in the west national regions", Journal of Nursing Research, vol. 22, pp. 3138-3139, Dec. 2008.

[3] R. Fu, "The research progresses of mental health in the elderly for nearly a decade", Journal of Nanyang Normal University (social science ed.), vol.11, pp. 104-107, Nov., 2012.

[4] Y.B. Zhu, The measurement and evaluation on the quality of life (QOL), People's Military Medical Press, Beijing, 2010.
[5] The statistics information center of the health ministry, the health services research in China in 2008 (analysis report of the fourth family health survey), Beijing Union Medical University Press, Beijing, 2009.

[6] L.Q. Wei, L.Z. Xu, Y. Wang, et al, "Multi-factor analysis for psychological factor in the quality of life among the empty-nest elderly in Baotou city", Journal of Baotou Medical College, vol.24, pp. 22-24, Jan. 2008.

[7] L.J. Zhou, A.H. Ou, Y.R. Lao, "The relationship between mental health index and quality of life among the elderly in Guangzhou", Chinese Journal of Gerontology, vol.28, pp.2463-2465, 2008. 